УДК 342.9

ББК 67.401.114

\title{
Правовая квалификация адресной рекламы
}

\author{
И.В. Кирюшина, Н.Ю. Лебедев ${ }^{1,2}$ \\ ${ }^{1}$ Алтайский государственный университет (Барнаул, Россия) \\ ${ }^{2}$ Сибирский университет потребительской кооперации \\ (Новосибирск, Россия)
}

\section{Legal Qualification of Address Advertising}

\author{
I.V. Kiryushina ${ }^{1}$, N.Yu. Lebedev ${ }^{1,2}$ \\ ${ }^{1}$ Altai State University (Barnaul, Russia) \\ ${ }^{2}$ Siberian University of Consumer Cooperation (Novosibirsk, Russia)
}

\begin{abstract}
Анализируются проблемные вопросы квалификации информации в качестве рекламы. Автором представлена позиция относительно квалификации адресной рекламы и таргетированной рекламы с точки зрения ее соответствия такому признаку рекламы, как адресованность неопределенному кругу лиц, позиция ФАС России, судебная практика по указанной теме. Предложено различать субъективную и объективную адресованность рекламного сообщения. При рассмотрении такого признака рекламы, как адресованность неопределенному кругу лиц, под неопределенным кругом следует понимать лиц, которые не могут быть заранее определены в качестве конкретной стороны правоотношения, возникающего по поводу реализации объекта рекламирования, и о которых заранее не известно, ознакомятся ли они с рекламой и откликнутся ли они на рекламное послание по поводу объекта рекламирования (например, приобретут ли рекламируемый товар). Даже узкий список адресатов рекламы будет являться неопределенным кругом лиц, поскольку заранее невозможно предположить, кто из адресатов воспримет рекламу и, как следствие, заключит договор с ее отправителем, в том числе в случаях отбора таких адресатов по определенным критериям и персонализации самого обращения.
\end{abstract}

Ключевые слова: реклама, неопределенный круг лиц, адресная реклама, таргетинг.

DOI 10.14258/izvasu(2018)3-25

Современные подходы к рекламе указывают на то, что распространение рекламы в расчете «на всех» неэффективно, поскольку большинство товаров предназначено для определенной категории потребителей, а следовательно, их реклама должна быть направлена на соответствующую аудиторию.
The article analyzes the problematic issues of legal qualification information as advertising. The author presents a position regarding the qualification of address advertising and targeted advertising from the point of view of its conformity to such a sign of advertising as an appeal to an indefinite circle of persons, the position of the FAS of Russia, judicial practice on the topic. It is suggested to distinguish between the subjective and objective orientation of the advertising message. When considering such a sign of advertising as an address to an indefinite circle of persons, an indefinite circle should be understood as persons who cannot be predetermined as a specific party to the legal relationship arising from the sale of the object of advertising, and of which it is not known in advance whether they will see the advertisement and whether they will respond to the advertising message about the object of advertising (for example, whether the advertised product will be purchased). Even a narrow list of addressees of advertising will be an undefined circle of persons, since it is not possible in advance to guess which of the addressees will receive the advertisement and, as a consequence, will conclude contracts with its sender, including in cases of selecting such addressees according to certain criteria and personalizing the appeal itself.

Key words: advertising, indefinite circle of persons, address advertising, targeting.

Это обусловило стремление маркетологов дифференцировать потребительскую аудиторию, которой будет адресована реклама, на мельчайшие сегменты по интересам, полу, возрасту, роду деятельности и т.д. Подобная дифференциация приводит к персонификации рекламных сообщений, что осложня- 
ет квалификацию подобной информации в качестве рекламной с точки зрения ее соответствия такому признаку рекламы, как адресованность неопределенному кругу лиц.

Анализ определения рекламы, данного в ст. 3 Федерального закона от 13 марта 2006 г. № 38-ФЗ «О рекламе» (далее - Ф3 «О рекламе») [1, ст. 3], позволяет выделить ряд признаков, характеризующих ту или иную информацию в качестве рекламной. Согласно данному определению, одним из признаков рекламы является ее адресованность неопределенному кругу лиц [2].

Легальное понятие неопределенного круга лиц в Ф3 «О рекламе» отсутствует. Федеральной антимонопольной службой России (далее - ФАС России) в письме от 5 апреля 2007 г. № АЦ/4624 высказана позиция, согласно которой «под неопределенным кругом лиц понимаются те лица, которые не могут быть заранее определены в качестве получателя рекламной информации и конкретной стороны правоотношения, возникающего по поводу реализации объекта рекламирования. Такой признак рекламной информации, как предназначенность ее для неопределенного круга лиц, означает отсутствие в рекламе указания о некоем лице или лицах, для которых реклама создана и на восприятие которых реклама направлена. Таким образом, под рекламой понимается определенная неперсонифицированная информация, направленная на продвижение определенного объекта рекламирования, даже если она направляется по определенному адресному списку» [3]. Указанная позиция поддерживается и в литературе [4, с. 14].

Вместе с тем судебная практика в указанной части неоднозначна. До недавнего времени суды придерживались позиции, согласно которой при распространении обращения заранее заданному числу адресатов такой признак рекламы, как адресованность неопределенному кругу лиц, отсутствует, следовательно, такая информация рекламой не является.

Так, Арбитражный суд Ростовской области по заявлению $3 \mathrm{AO}$ «Сбербанк» о признании недействительным решения управления Федеральной антимонопольной службы по Ростовской области от 24 марта 2015 г. по делу № 2565/04 указал, что направленное обществом СМС-сообщение не является рекламой, так как носило адресный характер [5].

По другому делу, по заявлению АО «Альфа-Банк» об оспаривании постановления ФАС России от 21 августа 2015 г. по делу об административном правонарушении, Арбитражный суд г. Москвы в решении от 30 марта 2016 г. по делу № А40-188149/2015-921515 изложил обоснованную позицию, согласно которой «под неопределенным кругом лиц понимаются те лица, которые не могут быть заранее определены в качестве получателя рекламной информации и конкретной стороны правоотношения, возникающего по поводу реализации объекта рекламирования, и о которых заранее не известно, откликнутся ли они на рекламное послание по поводу объекта рекламирования (например, приобретут ли рекламируемый товар)» [6].

Нередко на практике понятие «неопределенный круг лиц» отождествляют с понятием «все». На наш взгляд, такое отождествление ошибочно. Распространение любой информации предполагает адресата, определенного или не определенного заранее. Сфера распространения информации всегда ограничена либо техническими средствами, либо возможностями восприятия той или иной аудиторией, теми или иными рамками самой аудитории, например, знанием языка, на котором произносится реклама, способностью зрительного или слухового восприятия, уровнем интеллекта и т.д.

В этой связи следует различать субъективную и объективную адресованность рекламы. Субъективная адресованность - это направленность рекламы тому кругу лиц, на который рассчитан источник информации. Объективная адресованность - это возможность формирования интереса к информации у лиц, потенциально являющихся потребителями данной информации. Например, розничный магазин рассылает обладателям дисконтных карт рекламное сообщение о действующей скидке на товар. С точки зрения магазина, данное сообщение адресовано только обладателям дисконтных карт, круг которых определяется данными учета выданных дисконтных карт. Однако, с точки зрения привлечения внимания к объекту рекламирования, данная информация рассчитана на как можно более широкий круг потенциальных потребителей, который не ограничивается кругом владельцев дисконтных карт.

На наш взгляд, законодатель, определяя такой признак рекламы, как адресованность неопределенному кругу лиц, исходил из понимания объективной адресованности. В этом случае круг лиц, ознакомившихся с рекламой, является неопределенным, даже если реклама распространена среди определенного узкого круга адресатов, а направление рекламного сообщения конкретным лицам - это лишь способ адресной рассылки информации, при этом признак неопределенности круга лиц, на привлечение внимания которых направлена такая информация, не утрачивается.

Таким образом, понятие «неопределенный круг лиц» следует толковать исходя не из количества адресатов рекламных сообщений, а исходя из круга лиц, тем или иным образом способных заинтересоваться рекламным предложением. Кроме того, определяющим при квалификации той или иной информации в качестве рекламы является и со- 
держание рекламного сообщения, а не перечень адресатов. Иная точка зрения приводит к оспариванию квалификации сообщений в качестве рекламных и к возможности недобросовестного поведения рекламодателей и рекламораспространителей, в частности к игнорированию запретов рекламного законодательства, в т.ч.указанных в ст. 18 Ф3 «О рекламе».

Указание в рекламном обращении фамилии, имени и отчества адресата содержания самой рекламной информации в подавляющем большинстве случаев не затрагивает, что также не меняет квалификации такой информации в качестве рекламной. В этой связи заслуживает одобрения практика судов, квалифицирующих подобные обращения как рекламу.

Так, по делу по заявлению ООО «СМС Трафик» о признании незаконным постановления Федеральной антимонопольной службы России о привлечении общества к административной ответственности Арбитражный суд г. Москвы отклонил доводы заявителя ввиду следующего. Из материалов дела следует, в ФАС России поступило обращение гражданина Болотина А.Д. о распространении рекламы посредством СМС-сообщения следующего содержания: «Алексей Дмитриевич, для Вас кредит наличными банка Траст 300000 рублей. Специальное предложение до 03 июня! Для получения нужен только паспорт. Звоните сейчас по тел. 88001001144» в нашем офисе: Рыбинск, Герцена, 87, ком. 17, 74-77, тел. +7 $4855239027 »$.

Довод ООО «СМС Трафик» о том, что рассматриваемое СМС-сообщение не является рекламным и лишь доводит до сведения конкретного абонента информацию, было отклонено судами первой и апелляционной инстанции. Суды обосновали свою позицию тем, что «рассылка СМС-сообщений по каналам телефонной связи не может быть произведена иначе, как на конкретный абонентский номер, что позволяет говорить об адресном характере отправлений. Однако специфика связи с абонентами сама по себе не может являться основанием для признания информации, содержащейся в СМС-сообщениях, как предназначенной исключительно для конкретного абонента» [7].

Аналогичное, по сути, решение было принято судом по иску ООО «Филип Моррис Сэйлз энд Маркетинг». В постановлении Девятого арбитражного апелляционного суда №09АП-56873/2015 от 25 января 2016 г. по делу, возбужденному в связи с обращением гражданина, на абонентский номер которого поступило СМС-сообщение следующего содержания: «Привет, Кирилл! Не упустите шанс принять участие в захватывающем приключении. Всё самое интересное стартует 14 апреля на www.marlboro.ru/ mport. Курение убивает», суд отказал в удовлетворении требования ООО «Филип Моррис Сэйлз энд
Маркетинг» об отмене решения управления ФАС, полагавшего, что отправленное СМС-сообщение не является рекламой. Суд, мотивировав свое решение, указал, что информация содержит сведения о табачной продукции ООО «Филип Моррис Сэйлз энд Маркетинг», а именно о сигаретах Malboro. Такие сведения не носят персонализированного характера, несмотря на упоминание имени абонента, представляют интерес для неопределенного круга лиц и являются рекламой [8].

Ранее судами была высказана позиция, что «адресованность неопределенному кругу лиц в данном случае не имеет значения - в статье, регулирующей рекламу через сети электросвязи, слово «реклама» использовано в более узком значении, чем в общем определении. Информация, передаваемая через сотовую связь, всегда предполагает индивидуализированного через телефонный номер абонента, который ее получает» [9].

Таким образом, СМС-сообщения, телефонные звонки агентов по продажам, электронные письма с указанием ФИО адресата, хотя по форме выглядят как персональное обращение, являются рекламой и требуют в соответствии со ст. 18 Ф3 «О рекламе» предварительного согласия адресата на получение такой информации.

Но если при квалификации сообщения, направляемого определенным адресатам, в качестве рекламного судебная практика в последнее время выработала определенные подходы, то вопрос с признанием рекламными сообщений, адресованных четко определенной целевой аудитории, отобранной по конкретным признакам, остается открытым.

Развитие информационных технологий в настоящее время позволяет оперативно, практически в режиме реального времени, собирать и анализировать информацию о предпочтениях потенциальных потребителей товаров, работ, услуг и таким образом сужать целевую аудиторию для рекламных сообщений. Распространяемые технологии рекламы стремятся ко все большей дифференциации аудитории отдельных рекламных сообщений, вплоть до их персонализации по содержанию самого сообщения, что на языке маркетологов получило наименование «адресная реклама».

В этой связи следует различать понятия «адресованность рекламы» и «адресная реклама». Под «адресной рекламой» следует понимать рекламу, обращенную к конкретной аудитории, часто весьма узкой. Например, при рекламе косметики, предназначенной для возрастной группы женщин старше 40 лет, рекламодатель выберет способ рекламирования, при котором охват 40-летних женщин будет наиболее полным, например, соответствующий тематический журнал, интернет-сайт или телепрограмму, рассчитанные на женщин такого возраста. 
Мнение рекламодателя, что основным потребителем конкретного товара (работы, услуги) является четко определенная целевая аудитория, базируется на назначении товаров либо опросах и статистических наблюдениях. Но круг потребителей конкретного товара, круг покупателей такого товара и круг потребителей рекламы о таком товаре могут не совпадать. Поэтому термин «адресная реклама» следует понимать лишь как представление рекламодателя о наиболее перспективном круге потенциальных потребителей товара, определяющем наиболее эффективные способы и средства распространения такой рекламы.

Специфическим инструментом распространения адресной рекламы является таргетинг. Таргетинг в рекламе (англ. target - цель) - механизм, позволяющий выделять из всей имеющейся аудитории информационного канала только ту часть, которая удовлетворяет заданным рекламодателем критериям (целевую аудиторию), и показывать рекламу именно этой части аудитории.

Понятия «таргетинг» и «таргетированная реклама» получили наиболее широкое распространение в сфере интернет-продвижения объектов рекламирования. Процесс таргетинга представляет собой процедуру определения набора характеристик круга адресатов рекламных сообщений. В отличие от широко распространенной ранее контекстной рекламы, таргетированные рекламные объявления в сети Интернет показываются не в соответствии с содержанием страницы, а определенным группам пользователей. Этот инструмент позволяет выбирать аудиторию, которой будет демонстрироваться конкретное рекламное сообщение.

Персонализация рекламных сообщений стала вполне логичным этапом развития таргетированной рекламы. Если 5-10 лет назад автоматизированная рассылка персональных обращений являлась трудоемкой и затратной, то сегодня персональные письма и звонки рекламодателей становятся скорее правилом, обезличенный рекламный «спам» уступает место «спаму персонифицированному», при этом около половины содержат обращение по имени, а примерно каждое восьмое - обращение по имени, отчеству и фамилии. И если ранее такие обращения должны были быть оценены на предмет их соответствия признакам рекламы только с точки зрения их адресной направленности конкретным лицам, то теперь и с точки зрения их содержания - такое рекламное сообщение подготовлено с учетом индивидуальных интересов и предпочтений потенциального его получателя, а следовательно, адресовано персонально ему, что также ставит под вопрос возможность квалификации такого сообщения как рекламного.
Не затрагивая тему правомерности сбора и обработки персональных данных, осуществляемых для такого рода рассылок, остановимся на вопросе квалификации такой информации в качестве рекламной [10].

Рассматривая подобный «рекламный механизм» с правовой точки зрения на соответствие признаку адресованности неопределенному кругу лиц, следует учитывать следующее. В зависимости от целей, которых стремится достичь реклама, круг адресатов рекламы бывает широким или, напротив, узким. Вопрос о том, какой будет целевая аудитория рекламы, решает рекламодатель. В этой связи обособление круга лиц, которым направляется какаялибо информация персонально, не меняет ее квалификации в качестве рекламы, поскольку понятие неопределенного круга лиц как адресата рекламы не совпадает с понятием «целевая аудитория» рекламного послания.

Не меняет квалификации в качестве рекламы такой информации и отбор адресатов по определенным критериям, поскольку само рекламное сообщение создано не для конкретного адресата, а для любого отвечающего критериям отбора, при этом стороной в сделке может не стать ни один из адресатов, либо, напротив, сделку может заключить лицо, не находившееся в списке адресатов.

Добавление персонального обращения к адресату в содержание рекламного текста не лишает сообщение признака неперсонифицированности и не превращает рекламу в индивидуальное сообщение. Указание в рекламном обращении фамилии, имени и отчества адресата содержания самой рекламной информации в подавляющем большинстве случаев также не затрагивает.

На наш взгляд, при рассмотрении такого признака рекламы, как адресованность неопределенному кругу лиц, под неопределенным кругом лиц следует понимать лиц, которые не могут быть заранее определены в качестве конкретной стороны правоотношения, возникающего по поводу реализации объекта рекламирования (и в этой части согласиться с позицией ФАС России), и о которых заранее не известно, ознакомятся ли они с рекламой и откликнутся ли они на рекламное послание по поводу объекта рекламирования (например, приобретут ли рекламируемый товар). В данном случае даже узкий список адресатов рекламы будет являться неопределенным кругом лиц, поскольку заранее невозможно предположить, кто из адресатов воспримет рекламу и, как следствие, заключит договор с ее отправителем, в т.ч. в случаях отбора таких адресатов по определенным критериям и персонализации таких обращений. 


\section{Библиографический список}

1. О рекламе : Федеральный закон от 13.03.2006 № 38-Ф3 (ред. от 28.03.2017) // Собрание законодательства РФ. - 2006. - № 12. - ст. 1232.

2. Страунинг Э.Л. Правовые признаки рекламы // Закон. -2006 . - № 12.

3. О понятии «неопределенный круг лиц» : Письмо Федеральной антимонопольной службы от 05.04.2007 № АЦ/4624 // Экономика и жизнь. — 2007. — № 19.

4. Бадалов Д.С. Постатейный комментарий к Федеральному закону О рекламе / Д.С.Бадалов и др. - М., 2012.

5. Решение Арбитражного суда Ростовской области от 08.06.2015 по делу №А53-9616/2015 // СПС КонсультантПлюс.
6. Решение Арбитражного суда г. Москвы от 30.03.2016 по делу № А40-188149/2015-92-1515 // СПС КонсультантПлюс.

7. Постановление Девятого арбитражного апелляционного суда от 30.09.2015 № 09АП-38131/2015 по делу № А40-85856/15 // СПС КонсультантПлюс.

8. Постановление Девятого арбитражного апелляционного суда от 25.01.2016 № 09АП-56873/2015 по делу № А40-57742/15 // СПС КонсультантПлюс.

9. Постановление Федерального арбитражного суда Волго-Вятского округа от 29.08.2008 № А79-334/2008 // СПС КонсультантПлюс.

10. О персональных данных : Федеральный закон от 27.07.2006 № 152-Ф3 (ред. от 29.07.2017) // Собрание законодательства РФ. - 2006. - № 31 (ч. 1). - Ст. 3451. 